\title{
Assessment of BISAP Scoring System and C-Reactive Protein Analysis in Predicting Severity of Acute Pancreatitis
}

\author{
Aditya Vasant Ghunage ${ }^{1}$, Kiran Shrikant Kher ${ }^{2}$ \\ 1, 2 Department of General Surgery, JNMC, Sawangi Meghe, Wardha, Maharashtra, India.
}

\section{ABSTRACT}

\section{BACKGROUND}

Acute pancreatitis (AP) is a dormant deadly illness. The range of seriousness of the ailment goes from mellow self-restricting disease to an exceptionally lethal severe necrotizing pancreatitis. The disease has such a variable course that it may manifest as a simple pain in the abdomen to severe haemorrhagic pancreatitis with septicaemic shock, multi-organ dysfunction syndrome and ultimately leading to death. A cost-effective better prognosticative index is needed for the assessment of the severity of AP. Here in this study, we wanted to assess the role of BISAP scoring systems and CRP for analysis and comparing their values to determine the severity of AP and the prognosis of the disease.

\section{METHODS}

A prospective observational study was done on 83 patients diagnosed with AP after fulfilment of inclusion criteria. Patients were subjected to severity index, bedside index for severity in acute pancreatitis (BISAP) score and CRP calculation and statistical analysis was done with SPSS software.

\section{RESULTS}

In our study, AP was more prevalent in males $87.95 \%$ than females $12.05 \%$. AP was found to be more common in cases $\leq 40$ years of age, however, the mean age of presentation was $38.14 \pm 12.59$ years. We calculated the sensitivity and specificity of the BISAP score and C-reactive protein (CRP) by co-relating it with CT severity index as gold standard according to which the sensitivity was found to be $64 \%$ and specificity was found to be $85 \%$ for BISAP. The sensitivity and specificity of CRP was $64 \%$ and $85 \%$ respectively.

\section{CONCLUSIONS}

BISAP is an easy way to anticipate the severity of AP within 24 hours. It also helps to prognosticate AP. CRP can also be used to aid BISAP in the assessment of severe acute pancreatitis (SAP).

\section{KEY WORDS}

Acute Pancreatitis, BISAP, CRP.
Corresponding Author: Dr. Aditya Vasant Ghunage, Department of General Surgery, JNMC, Sawangi Meghe, Wardha, Maharashtra, India. E-mail: aadityaghunage@gmail.com

DOI: $10.14260 /$ jemds/2021/610

How to Cite This Article: Ghunage AV, Kher KS. Assessment of BISAP scoring system and $C$-reactive protein analysis in predicting severity of acute pancreatitis. J Evolution Med Dent Sci 2021;10(35):2985-2988, DOI: $10.14260 /$ jemds/2021/610

Submission 23-11-2020,

Peer Review 01-07-2021,

Acceptance 08-08-2021,

Published 30-08-2021.

Copyright (C) 2021 Aditya Vasant Ghunage et al. This is an open access article distributed under Creative Commons Attribution License [Attribution 4.0 International (CC BY 4.0)] 


\section{BACKGROUND}

Acute pancreatitis (AP) is a dormant deadly illness. The range of seriousness of the ailment goes from mellow selfrestricting disease to an exceptionally lethal severe necrotizing pancreatitis. ${ }^{1}$ The disease has such variable course that it may manifest as a simple pain in the abdomen to severe haemorrhagic pancreatitis with septicaemic shock, multi-organ dysfunction syndrome and ultimately leading to death.

Many scoring systems have been introduced from time to time for the prediction of the severity of AP based on various parameters. Ranson's standards and Modified Glasgow score use the information that aren't regularly gathered during hospitalization. Also, these two criteria's require 48 hours, consequently missing possibly important early remedial window. Now APACHE - II is the most broadly used prognostic score for AP but its complex nature and gathering of large figures of parameters makes it less favourable. BISAP is a straightforward bedside prognosticative score which involves routine investigation of admitted patients. ${ }^{2}$

$\mathrm{Wu}$ et al. introduced a new framework called as BISAP scoring system in the year 2008. It is simple. Clinical data can be obtained at the time of presentation to an emergency room. It can detect the severity of AP before time and also help to identify patients in danger of death. Papachristou et al. gave its sensitivity of $37.5 \%$ and specificity of $92.4 \%$ when the score was 3 . He also gave the PPV of $57.7 \%$ and NPV of $84.3 \%{ }^{3}$

BISAP, a new scoring system which was initially abbreviated with five markers - Blood urea nitrogen, impaired mental status, systemic inflammatory response syndrome (SIRS), age and pleural effusion and was later validated as BISAP.4 Each parameter of BISAP is as follows, BUN, impaired mental status, SIRS, age, presence of pleural effusion. ${ }^{4}$

\section{BISAP Score}

1. BUN - > 25mg / dL

2. Impaired mental status - GCS $<15$

3. SIRS

4. Age

5. Presence of pleural effusion

SIRS is explained as presence of $2 \geq$ of following,

Pulse - > $90 \mathrm{bpm}$, respiratory rate $>20 / \mathrm{min}$, or PaCO2 $<$ $32 \mathrm{mmHg}$, temperature $>38^{\circ} \mathrm{C}$ or $<36{ }^{\circ} \mathrm{C}$, WBC $<4,000$ or $>12,000$ cells / mm 3 or $>10 \%$ immature bands, age more than sixty years, pleural effusion seen on imaging. 4

Above 5 parameters have one point each constituting a total score of $5 .{ }^{4} \mathrm{C}$ - Reactive Protein(CRP) is a neutrophiltriggering peptide (acute phase protein) manufactured in the liver cells by multiple cell lines. Its manufacturing is brought about by the liberation of interleukins (IL) 1 and 6.5 The highest value of CRP is found usually in bacterial infections about $>1000$ times. Once the stimulant is gone its values fall over 18 - 20 hours (near to half-life of CRP). Factors affecting the normal level of CRP include smoking, high lipid levels, weight, hypertension etc. the average normal CRP value in a healthy person is $0.8 \mathrm{mg} / \mathrm{dl}$. It may vary from person to person as a result of polymorphism in the gene of CRP6. Many researchers assessed this marker as an indicator for the seriousness of acute pancreatitis when calculated on hospitalization, 24,48 or $72 \mathrm{~h}$ after hospitalization, and practised variables as cut-off levels. ${ }^{1}$ In this study we have taken CRP cut-off value as $\geq 150 \mathrm{mg} / \mathrm{L}^{1}$

The fast response of CRP to changes in the severity of inflammatory provocation propose that it may be significant in the evaluation and monitoring of AP. The clinical issue specifically compelling was to test whether CRP estimations could mirror the seriousness of the attack and in this manner give an admonition of the likely evolution of pancreatic collections (pseudocyst, abscess, and necrosis), which can arise insidiously and be deadly. ${ }^{5}$

\section{Objectives}

1. To assess the role of BISAP score in AP.

2. To analyse the CRP in cases of AP.

3. To compare BISAP score with CRP analysis in predicting the severity of AP

\section{METHODS}

It is a prospective observational study and a total of 83 patients with acute pancreatitis admitted to our Acharya Vinoba Bhave Rural Hospital Sawangi (Meghe) under the Department of General Surgery, Wardha were included in this study from December 2018 to September 2020.

\section{Inclusion Factors}

All patients who got admitted to Acharya Vinoba Bhave Rural Hospital with acute pancreatitis based on clinical, USG and CT scan findings.

\section{Exclusion Factors}

1. Patients admitted with acute pancreatitis who were associated with other diseases at the time of admission such as connective tissue disorder vasculitis or rheumatoid arthritis, burns, trauma, infections like tuberculosis chronic inflammatory conditions like CRF.

2. Patients who were on statin therapy.

3. Patients who had h / o myocardial infarction within the last 6 months.

\section{Source of Data}

Patients were evaluated clinically and included in the study after applying the proper inclusion and exclusion criteria

This study was conducted after the approval of the Ethics Committee Department of Medical Education, Jawaharlal Nehru Medical Sciences, Deemed University, Sawangi (Meghe), Wardha and written consent was obtained from the patient.

\section{Procedure for Collection of Data}

- Prior consent was taken for the study

- Data was collected on a pre-tested proforma which included:

- History taking.

- Clinical examination. 
- Investigations (which are described below)

All patients were subjected to routine investigations:

- Complete Blood Picture

- Blood Urea Nitrogen

- C - Reactive Protein

- Chest X - ray and / or USG - Thorax

- USG - Abdomen

- Serum Amylase and Lipase

Relevant special investigations: CECT - Abdomen

\section{Balthazar Scoring System - CTSI}

Grade A: Pancreas appear normal or mild inflammation of Pancreas - 0

Grade B: Focal / diffuse pancreatitis without surrounding inflammation - 1

Grade C: grade B + surrounding inflammation - 2

Grade D: grade C + unilocular fluid collection - 3

Grade E: grade $\mathrm{C}+$ more than one fluid collection with retroperitoneal gas shadow -4

Score for necrosis- Less than $30 \%$ necrosis -2, $30 \%-50 \%$ necrosis - 4, more than $50 \%-60 \%$ necrosis- 6

CTSI-

0 - 3 mild pancreatitis

4 - 6 moderate pancreatitis

7 - 10 severe pancreatitis

We have included the CT severity index as a gold standard investigation to compare BISAP and CRP analysis for analysing the severity of AP.

\section{Statistical Analysis}

By Statistical package for social sciences (SPSS) software, $\mathrm{v}$ 20.0 and GraphPad Prism v 7.0

We applied sensitivity and specificity tests along with positive predictive value and negative predictive value to get the inference.

\section{RESULTS}

\begin{tabular}{|ccc|}
\hline BISAP & No of Patients & $\mathbf{\%}$ \\
Severe $\geq 3$ & 33 & 39.76 \\
Mild $<3$ & 50 & 60.24 \\
Total & $\mathbf{8 3}$ & $\mathbf{1 0 0}$ \\
\hline Table 1. Distribution of Patients According to BISAP Score \\
\hline
\end{tabular}

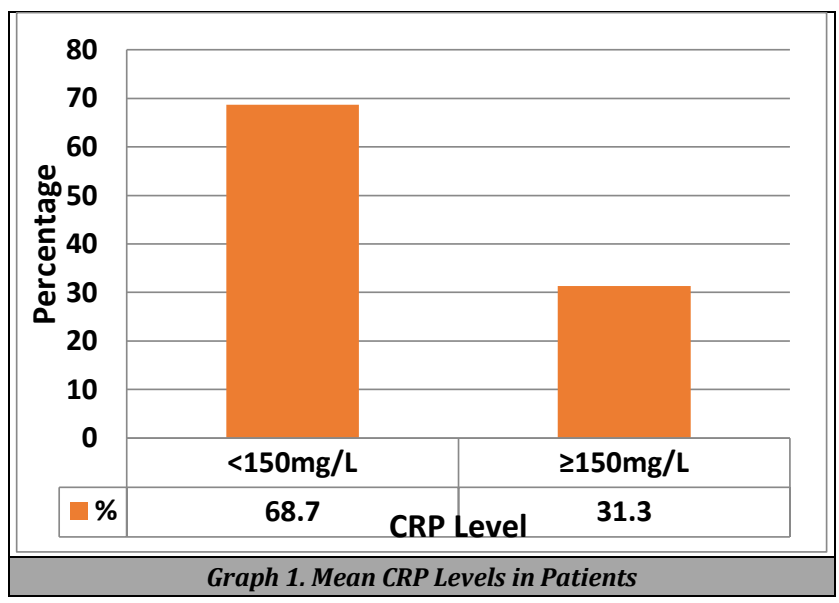

On admission, BISAP score was calculated and was found to be severe in $39.76 \%$ of patients whereas it was found to be mild in $60.24 \%$ of cases.

We calculated CRP in all patients on admission, at 24, 48, 72 hours and calculated mean values of CRP. With cut off values more than or equal to $150 \mathrm{mg} / \mathrm{L}, 68.7 \%$ cases were below $150 \mathrm{mg} / \mathrm{L}$ and about $31.3 \%$ cases were above the cut off value.

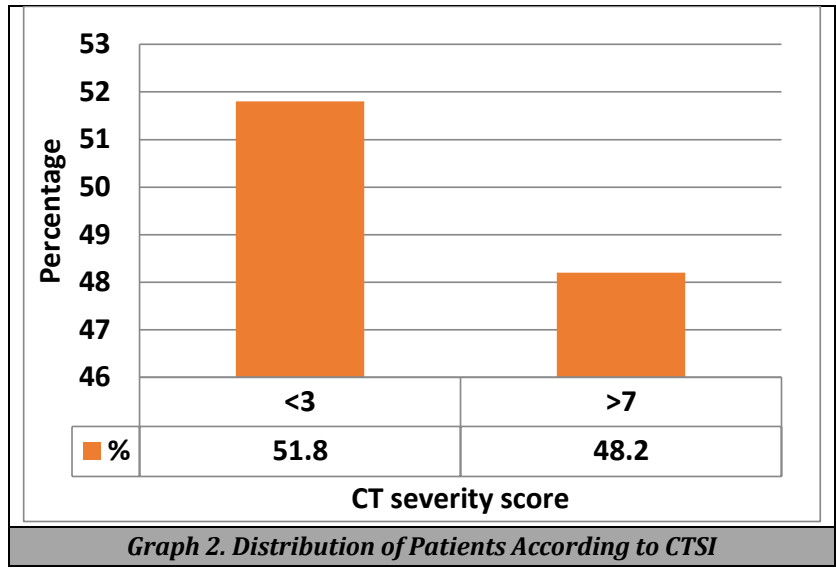

In our study, about $51.8 \%$ of cases were having a CT severity score less than or equal to 3 whereas $48.2 \%$ of cases were having a score more than or equal to 7 .

\section{DISCUSSION}

Acute pancreatitis involves inflammation of the pancreas along with multi-organ impairment thereby causing an increase in the death rate. ${ }^{1}$ The inflammation may get resolved on its own with proper treatment otherwise it can advance to cause complications finally resulting in death. Hence newer scoring systems are being framed to prevent such progression. ${ }^{1}$

In our study, AP was more prevalent in males $87.95 \%$ than females $12.05 \%$, the results are consistent with the study done by Bung $\mathrm{Y} \mathrm{K}$ et al. in which there were $75 \%$ males and $25 \%$ females. AP was found to be more common in cases $\leq 40$ years of age, however, the mean age of presentation was $38.14 \pm 12.59$ years. Age distribution was consistent with results reported by Hagjer $S$ et al. as the mean age of presentation was the late thirties. ${ }^{2}$

Age, GCS, SIRS are utilized in BISAP as well as APACHE II whereas adding BUN and PE increase the accuracy to diagnose SAP and to measure death rate. As per the revised Atlanta classification, local complications, extra-pancreatic organ impairment strongly point towards severe disease and prolonged hospitalization. ${ }^{7}$ In our study, on admission BISAP score was calculated and was found to be severe in $39.76 \%$ of patients whereas it was found to be mild in $60.24 \%$ cases. The results were similar to a study done by Bung YK et al. where he reported $75 \%$ cases with BISAP $<3$ (mild) and 25 $\%$ cases with BISAP $\geq 3 .^{2}$ (see Table 1 )

We calculated CRP in all patients of AP on admission, 24 hrs, 48 hrs, 72 hrs respectively. Mean CRP levels were calculated, and patients were categorized considering a cutoff value of $\geq 150 \mathrm{mg} / \mathrm{L}$ as severe acute pancreatitis. ${ }^{8}$ There 
were about $68.7 \%$ of patients who had mean CRP levels below $150 \mathrm{mg} / \mathrm{L}$ whereas $31.3 \%$ patients had CRP values $\geq$ $150 \mathrm{mg} / \mathrm{L}$. (see Graph 1)

In 1985 Balthazar et al. built up a scoring framework for AP dependent on a whole assessment of the shape, thickness and dimensions of the pancreas, pancreatic necrosis, peripancreatic assemblage in computed tomography to prognosticate in AP. 9

In 1990 Balthazar adjusted his scoring framework by adding the intensity of pancreatic necrosis. This altered index would be wise to exactness in prognostication than his previous scoring framework. CT severity is an aggregate scoring of pancreatic provocative changes and measures of necrosis. ${ }^{10}$

\begin{tabular}{|c|c|c|c|}
\hline \multirow{2}{*}{ BISAP Score } & \multicolumn{2}{|c|}{ CTSI Score } & \multirow{2}{*}{ Total } \\
\hline & Positive $\geq 7$ & Negative $\leq 3$ & \\
\hline Positive $\geq 3$ & 27 & 6 & 33 \\
\hline Negative $<3$ & 15 & 35 & 50 \\
\hline Total & 42 & 41 & 83 \\
\hline \multicolumn{4}{|c|}{ Table 4. Sensitivity and Specificity of BISAP Score } \\
\hline
\end{tabular}

We calculated the sensitivity and specificity of BISAP score by co-relating it with the CT severity index as gold standard according to which the sensitivity was found to be $64 \%$ and specificity was found to be $85 \%$ with PPV and NPV of $81 \%$ and $70 \%$ respectively. Vaidya et al. reported sensitivity of BISAP score $\geq 3$ as $62.50 \%$ and specificity of $92.31 \%$ with PPV and NPV of $76.9 \%$ and $85.71 \%$ respectively which can be due to smaller sample size. ${ }^{11}$

\begin{tabular}{|c|c|c|c|}
\hline \multirow{2}{*}{ CRP } & \multicolumn{2}{|c|}{ CTSI } & \multirow{2}{*}{ Total } \\
\hline & Positive $\geq 7$ & Negative $\leq 3$ & \\
\hline Positive ( $\geq 150 \mathrm{mg} / \mathrm{L}$ ) & 24 & 4 & 28 \\
\hline Negative $(<150 \mathrm{mg} / \mathrm{L})$ & 16 & 39 & 55 \\
\hline Total & 40 & 43 & 83 \\
\hline \multicolumn{4}{|c|}{ Table 5. Sensitivity and Specificity of CRP } \\
\hline
\end{tabular}

Co-relation of CRP and CTSI was done and sensitivity and specificity were calculated as per data. The sensitivity and specificity of CRP was $64 \%$ and $85 \%$ respectively. The PPV and NPV of CRP came out to be $81 \%$ and $70 \%$ respectively. Our results were similar to the results of the study done by Cho JH et al. on 161 patients where sensitivity, specificity, PPV and NPV were reported as 53.3 \%, 94.3 \%, $66.7 \%, 90.4$ $\%$ respectively. ${ }^{12}$

Chen et al. demonstrated the merits of BISAP such as it is simpler, faster than older scoring systems and it performs like other systems to assess SAP. ${ }^{3}$

\section{CONCLUSIONS}

BISAP represents the easiest way to assess the severity of AP within 24 hours providing enough time to initiate aggressive treatment. It also provides an easy way to determine the prognosis of the patients with AP. Though a nonspecific mediator of inflammation, CRP also helps to determine the prognosis of AP. CRP analysis can also be used to aid BISAP in the assessment of SAP.

\section{Limitations}

1. Small sample size.
2. BISAP has fixed parameters like age, pleural effusion due to which despite the milder attack in the age above 60 , it can falsely detect the severity of AP in elderly patients.

3. Since CRP is a nonspecific mediator of inflammation, it can be raised in any kind of infection as well as inflammation.

4. Though CRP aids in the assessment of severity, it's not available at every institute.

Data sharing statement provided by the authors is available with the full text of this article at jemds.com.

Financial or other competing interests: None.

Disclosure forms provided by the authors are available with the full text of this article at jemds.com.

\section{REFERENCES}

[1] Meher S, Mishra TS, Sasmal PK, et al. Role of biomarkers in diagnosis and prognostic evaluation of acute pancreatitis. J Biomark 2015;2015:519534.

[2] Bung YK, Neeralagi CS, Suggaiah L, et al. A prospective study to predict the severity of acute pancreatitis by BISAP score. Int Surg J 2017;4(7):2221-6.

[3] Chen L, Lu G, Zhou Q, et al. Evaluation of the BISAP Score in predicting severity and prognoses of acute pancreatitis in Chinese patients. Int Surg 2013;98(1):612.

[4] Bezmarević M, Kostić Z, Jovanović M, et al. Procalcitonin and BISAP score versus $\mathrm{C}$ - reactive protein and APACHE II score in early assessment of severity and outcome of acute pancreatitis. Vojnosanit Pregl 2012;69(5):425-31.

[5] Mayer AD, McMahon MJ, Bowen M, et al. C reactive protein: an aid to assessment and monitoring of acute pancreatitis. J Clin Pathol 1984;37(2):207-11.

[6] Sproston NR, Ashworth JJ. Role of C - reactive protein at sites of inflammation and infection. Front Immunol 2018;9:754.

[7] Hagjer S, Kumar N. Evaluation of the BISAP scoring system in prognostication of acute pancreatitis - a prospective observational study. Int J Surg 2018;54(Pt A):76-81.

[8] Trivikraman R, Chayampurath R, Malieckal JI. Validity of bedside index of severity in acute pancreatitis score in comparison with $\mathrm{C}$ reactive protein in assessing the severity of acute pancreatitis. Int J Res Med Sci 2016;4(12):5248-51.

[9] Balthazar EJ, Ranson JH, Naidich DP, et al. Acute pancreatitis: prognostic value of CT. Radiology 1985;156(3):767-72.

[10] Subramanian S, Thyagarajan M, Thiyagarajan M, et al. Comparison of BISAP (Bedside Index for Severity of Acute Pancreatitis) versus BALTHAZAR CTSI (Computed Tomography Severity Index) scoring in predicting the severity in acute pancreatitis. Med Sci 2020;24(101):7582.

[11] Vaidya Y, Vaithianathan R, Manickam R. Comparative evaluation of the BISAP Score with CT severity index in predicting the severity of acute pancreatitis. Indian J Surg 2018;80:353-8.

[12] Cho JH, Kim TN, Chung HH, et al. Comparison of scoring systems in predicting the severity of acute pancreatitis. World J Gastroenterol 2015;21(8):2387-94. 